\title{
Study on the Impact of the Internet on the Social Network of the Chinese Migrant Children
}

\author{
ZHUANG Xi
}

Author

Zhuang Xi, Ph.D.,Associate Professor, School of Journalism and Communication, Nanjing Normal University

Email: zhuangxinj@163.com

Address: School of Journalism and Communication, Nanjing Normal University, Ning Hai Road 122\#, Nanjing, Jiang su Province, 210036

This paper is a part of the research project "Study on Migrant Children's Media Use and their Social Integration"(Project number: 10CXW027), subsidized by Chinese National Social Science Youth Fund.

\section{Keywords}

migrant children internet social network online game

\begin{abstract}
Immigration and settling down in a new society can be one of the most dynamic and complex processes in an individual's life. Personal and cultural changes are enmeshed in continuous processes of discovery, upheaval and crisis. ${ }^{1}$ With the advancement of urbanization, a lot of migrant children followed their parents to enter the city society in China. ${ }^{2}$ Eventually, they became a group of stranger in the rural-urban fringe.The report of national urban migrant children in China issued in 2013 showed the number of migrant children increased rapidly, reaching the the scale of 35.81 million. $^{3}$

The migrant situation in contemporary China is directly linked to two historical phenomena: the recent opening of the Chinese economy to market-style reforms, and long-term constraints on population mobility and the distribution of state-sponsored goods and services through a system of residence permits called the hukou system. ${ }^{4}$

Geographical migration not only cut off the geopolitical, kinship ties of the migrant children to some extent, but also broke the individual's social network of relationships. This kind of fracture has a certain effect on childhood development and the children's future social interaction.

From the psychological perspective, migrant children are in a critical period of development in social interaction. ${ }^{5}$ They are in an urgent need to find new ways to complete the reconstruction of the network of relationships. The motivation of the children to develop social network is more related to spontaneous demands of psychological or cultural aspects, rather than utilitarian purpose of the adults. Thus, how to find a way to build their social network and then accumulate enough social capital in the city has become an important issue of the social integration of the group.
\end{abstract}


Quantitative questionnaire survey and semi-structured, in-depth interview conducted with migrant children were the primary research methods adopted in this study. The sampling survey, was mainly conducted in primary and secondary schools. The whole process is divided into two rounds. The first round of the survey was conducted from November 2009 to March 2010, the research mainly concentrated in Nanjing. The second round of the survey was conducted from June 2013 to January 2014, the research hold in Nanjing, Shanghai and Guangzhou. A total of 2396 questionnaires were returned, with 2268 valid, including 1537 migrant children and 731 urban children as the reference sample.Male ratio was $52.8 \%$, the proportion of girls was $47.2 \%$, from the ages of nine to fourteen. Given the reality, the situation of migrant children's education is divided into two different categories, one is enrolled in some special schools for migrant children, one is enrolled in some urban school on a temporary basis. The former is a typical "homogeneous" combination of education situation, the latter is a typical "heterogeneous" combination of education contexts. In those school environment, life often exhibit different characteristics to the migrant children. ${ }^{6}$ To make a reasonable interpretation for the real living conditions of migrant children, the study took these two types of students into account in the sample. The migrant children interviewed in the semi-structured, in-depth interview part represent different profiles of the population. The snowball method applied in selecting the sample sought to attain a balance according to three primary variables: length of residence in the city, gender and age.

The analysis of the findings is presented in four sections:

1. The findings revealed that the internet was one of the favorite media for migrant children, although most of them began to use it only after immigration to the city.

2. The migrant children use the Internet to achieve the re-aggregation of strong relationship network. The study showed that 28.4 percent of migrant children usually can not meet and chat with their friends face to face. Most of the migrant children "usually communicate with friends via online chat tools ". QQ chat tool is the main one they chose to usel. Among the migrant children's online chat list, classmates, fellow-villagers, relatives accounted for a large proportion. Internet provided the homogeneous groups a virtual platform to get together and share feelings. This link is not blurred, but the strengthening of the reality ties.

3. The internet has become an important channel for the migrant children to expand the weak ties ${ }^{7}$ of social network,though the expansion of weak ties based on internet is difficult to turn virtual into the real. The migrant children' s enthusiasm of using the internet to expand their social circle had some relation with their age and the real amount of peer interaction channels. Interviews showed that migrant children's exchanges with the network of weak ties mainly focused on aspects of sharing of information, such as the information of schools, certain events, as well as the views of some pop stars. But it's still pretty hard for the web-based weak ties to expand into the real level interaction. Network pseudonym made contacts and relations between anonymous individuals fragile. It is difficult to develop to further practical level. And once the expansion of weak ties got frustrated, migrant children tend to be more retreated into their homogeneous groups.

4. Migrant children enjoyed alternative exchanges in the participation of some online role-playing-games. ${ }^{8}$ Migrant boys prefered games of conquer type, 
accumulating communicative capital between peers in obtaining alternative interactive experience ${ }^{9}$; though the girls prefer online virtual communities games, having fun from the integration of the dreamy community. However, the compensation got from online games is apt to make the group more addicted to the internet.

In summary, the new media weaved a reconstructive field of public communication networks for the migrant children. Here, the individual could expand the scope of social interaction to some extend, getting reach to the circle of urban people which is far away from them in reality. But after all, since the online media contact is virtual, getting too immersed into it is no good for the healthy development of the children. Media's funtion in remodeling the migrant children is noteworthy. And the social problems cencerning the media behavior of the migrant children is worth further studying.

\section{References}

[1]Nelly Elias and Dafna Lemish (2008).Media Uses in Immigrant Families: Torn between 'Inward' and 'Outward' Paths of Integration. International Communication Gazette, 70, 21

[2] Zhang,Li Zhong (2007). Social integration of migrant children in the city and its countermeasures. South China Rural Area, 2,44-47.

[3] Li,Haixiu(2013). "migrant childre more than 35 million", Guang Ming Daily, 2013.5.16

[4] Woronov,T.E..In the Eye of the Chicken: Hierarchy and marginality among Beijing'smigrant schoolchildren.Ethnography,2004 (5):289-313

[5] Lin, Chongde (2008).Developmental psychology. Hangzhou: Zhejiang Education Publishing House.

[6] Ma, Liang (2007). Analysis on the interactive process between the migrating children compulsory education policy and the reality. In Gu,Xuebin,Ruan Zengyuanqi (ed.), Practice-based Chinese local social work research. Beijing: Social Sciences Academic Press.

[7] Mark S. Granovetter(1973). The Strength of Weak Ties. The American Journal of Sociology, 78 (6): 1360-1380.

[8] Yang, Yinjuan (2009) An Empirical Study on the Intrinsic Motivation of Children's Participation in Mole Online Game. Journal of International Communication, 12, 99-104.

[9] Lin, Yuling (2007). Schoolchildren's Game-Playing Practices and Gender Construction: A Case Study of Elementary School Pupils in a Remote Area. Mass Communication Research (Taipei), 90, 43-99. 